\title{
COMPETÊNCIAS CONVERSACIONAIS EM AMBIENTES DE REDAÇÕES JORNALÍSTICAS ${ }^{l}$
}

\section{Conversational competencies in newsroom environments}

\section{Competencias conversacionales en ambientes de redacciones periodísticas}

Ana Cristina Carneiro dos Santos

Doutoranda do Programa de Pós-Graduação em Ciência da Informação da UnB (Universidade de Brasília)

anacarneiro1000@gmail.com

Gentil José de Lucena Filho
Pesquisador-chefe do Labcon: Laboratório de Inteligência Conversacional
gentil@labconbrasil.com

Gheorghita Ghinea

Professor da Brunel University London (United Kingdom) george.ghinea@brunel.ac.uk

Lillian Maria Araújo de Rezende Alvares

Professora do Programa de Pós-Graduação em Ciência da Informação da UnB (Universidade de Brasília)

lillianmariaalvares@gmail.com

Ébida Rosa dos Santos Pesquisadora no Centro de Estudos em Comunicação, Tecnologia e Política da UnB

(Universidade de Brasília) ebidasantos@gmail.com

Maria de Fátima Ramos Brandão

Professora do Departamento de Ciência da Computação da UnB (Universidade de Brasília) fatimabrandao@gmail.com

\footnotetext{
${ }^{1}$ Registra-se aqui os melhores agradecimentos à CAPES (Coordenação de Aperfeiçoamento de Pessoal de Nível Superior) pela concessão da bolsa de estudos durante o período de doutorado sanduíche em Londres; à Universidade de Brasília (Brasil) e à Brunel University London (UK) pelo apoio fornecido para o desenvolvimento deste trabalho. Esta publicação também faz parte das ações realizadas no âmbito do Projeto MDM que propôs um estudo exploratório nos campos da Comunicação, Ciência da Informação e Ciência da Computação da Universidade de Brasília. O projeto contou com o apoio financeiro do Programa Ciência sem Fronteiras CAPES/CNPq, Processo: 88881.068354/2014-01; e da CAPES, Processo: 88887.144822/2017-00.
} 


\title{
Resumo
}

A pesquisa investiga a importância das conversas e seu potencial de contribuição para as rotinas de produção da notícia em ambientes de redações jornalísticas. Tendo como base a Ontologia da Linguagem, inicialmente caracterizou-se como descritiva, aplicada e exploratória. Ao desenvolver o instrumento de análise, denominado Matriz de Sentidos, a pesquisa passou a ser considerada também metodológica, tendo como base a Teoria Fundamentada nos Dados (TFD). Uma das contribuições deste trabalho está em situar a importância das conversas, dando-lhes visibilidade formal, teórica, filosófica e metodológica no processo de produção das notícias. A Matriz de Sentidos contribuiu para a explicação de padrões de comportamentos e demonstrou ser um instrumento que pode ser customizado e replicado para outros contextos em que as conversações possuam um papel relevante.

Palavras-chave: Ontologia da linguagem. Redações jornalísticas. Competências conversacionais.

\begin{abstract}
The research investigates the importance of the conversations and their potential to contribute to the news production routines in journalistic newsroom. Based on the Ontology of Language, this study was initially characterized as a descriptive, applied and exploratory research. By developing the instrument of data analysis, called Matrix of Senses, the research started to be considered also methodological, based on Grounded Theory Methodology (GTM). One of the important contributions of this work is to situate the importance of the conversations, giving them formal, theoretical, philosophical and methodological grounded visibility for the news production process. The developed Matrix of Senses contributed to the explanation of patterns of behavior and presents itself as an instrument that can be customized and replicated to other contexts in which the conversations play a relevant role.
\end{abstract}

Keywords: Ontology of language. Newsrooms. Conversational competencies.

\section{Resumen}

La investigación investiga la importancia de las conversaciones y su contribución a las rutinas de producción de la noticia en ambientes de redacción periodística. Con base en la Ontología del Lenguaje, inicialmente se caracterizó como descriptiva, aplicada y exploratoria. Al desarrollar el instrumento de análisis, denominado Matriz de Sentidos, la investigación pasó a ser considerada también metodológica, teniendo como base la Teoría Fundamentada en los Datos (TFD). Una de las contribuciones de este trabajo está en situar la importancia de las conversaciones, dándoles visibilidad formal, teórica, filosófica y metodológica en el proceso de producción de las noticias. La Matriz de Sentidos contribuyó a la explicación de patrones de comportamientos y se presenta como un instrumento que puede ser personalizado y replicado para otros contextos en que las conversaciones tengan un papel relevante.

Palabras-clave: Ontología del lenguaje. Redacción periodística. Competencias conversacionales. 


\section{INTRODUÇÃO}

Processos de comunicação em redações jornalísticas envolvem aspectos ontológicos determinantes para seu sucesso. Apoiada na filosofia de Heidegger, o termo ontologia a que se refere este artigo, considera as possibilidades do "ser" em sua perspectiva histórica e no seu potencial de criação. De maneira mais específica, remete ao universo da Ontologia da Linguagem, que estuda a natureza do "ser" humano e suas novas formas de convivência.

Este artigo é parte de um estudo exploratório que investiga as conversações e considera suas características universais e gerais. Universais porque em qualquer lugar do mundo, independentemente do idioma, as pessoas conversam. Gerais porque ações como pedidos, ofertas e promessas, ainda que em locuções, credos, etnias ou classes sociais diferentes, ilocucionariamente possuem o mesmo sentido (SEARLE, 1980).

Partindo dessas características, investiga-se a importância das conversas, em particular, conversas para coordenação de ações e realização de compromissos relacionados ao processo de produção da notícia em ambientes de redações jornalísticas. Sua relevância está no potencial de contribuição para a eficiência e eficácia das rotinas de produção da notícia, profundamente modificadas e vulnerabilizadas pelas novas formas de configuração das redes de colaboração e seus novos meios e suportes de comunicação digital.

\section{FUNDAMENTAÇÃO TEÓRICA}

Influenciado pelas contribuições de Nietzsche, Wittgenstein, Heidegger, Maturana e Flores, o sociólogo e filósofo chileno Rafael Echeverría (1997), propõe uma articulação específica e particular das contribuições desses autores e, apoiado por elas, oferece uma nova concepção integradora do fenômeno humano, denominada Ontologia da Linguagem.

A Ontologia da Linguagem possui três postulados: i) a interpretação dos seres humanos como seres linguísticos; ii) a interpretação da linguagem como geradora; e iii) o entendimento de que os seres humanos se desenvolvem na linguagem e por meio dela (ECHEVERRÍA, 1997). Para embasar o desenvolvimento deste artigo, algumas abordagens e relações temáticas entre conceitos relevantes para a compreensão do significado de conversas efetivas, no âmbito da Ontologia da Linguagem, são descritas a seguir.

\subsection{Organizações como redes de compromissos}

Na década de 1980, Winograd e Flores (1988) já trabalhavam com a ideia, posteriormente reforçada por autores como Echeverría (2002, 1998, 1997), de que 
organizações existem como redes de compromissos diretivas. As diretrizes (que incluem pedidos, ofertas e consultas) e os compromissos (que incluem promessas, aceitações e rejeições) são responsáveis pela realização das tarefas e, consequentemente, pela obtenção de resultados individuais e organizacionais. Tais diretrizes e compromissos são constituídos por "atos de fala", teoria inicialmente elaborada por John Langshaw Austin (1911-1960) e posteriormente desenvolvida por John Searle (1980), que se refere à linguagem como uma forma de ação.

Para Austin (1962, p. 13), "todo dizer é um fazer" e é também "uma forma de interagir com o mundo". Locucionários (ato de pronunciar um enunciado; o que é dito), ilocucionários (ato realizado por meio da pronúncia de um enunciado; ações embutidas no que é dito) ou perlocucionários (efeitos produzidos), os atos de fala, de acordo com Winograd e Flores (1988), correspondem ao núcleo de todo o processo de trabalho realizado nas organizações por meio das conversações.

\subsection{Compromissos conversacionais}

Conforme Kofman (2002, v. II), um indivíduo ou uma equipe evidencia sua capacidade de cumprir compromissos na efetividade com que realiza suas tarefas, estabelece relações de confiança necessárias para cumpri-las e investe na garantia da identidade das pessoas, grupos ou organizações envolvidas nesses relacionamentos e tarefas. De acordo com o autor, os compromissos conversacionais afetam três níveis - Tarefa (T), Relação (R) e Identidade (I). Descreve-se a seguir, com base em Kofman (2002, v. II) e Lucena Filho et al. (2012), cada um deles:

- T: o objetivo é coordenar ações para obter os resultados desejados. Refere-se à tarefa com que o indivíduo ou grupo se compromete a executar. Preocupa-se com a qualidade dos resultados dessa execução.

- R: o objetivo é gerar vínculos de confiança, a fim de possibilitar coordenações efetivas de ações futuras. Preocupa-se com a qualidade dos relacionamentos entre as pessoas.

- I: o objetivo é agir com integridade e dignidade. Preocupa-se com a coerência entre os compromissos, intenções e ações de um indivíduo e com a sua dignidade.

$\mathrm{Na}$ perspectiva da Ontologia da Linguagem, os compromissos conversacionais correspondem a uma coordenação de ações, onde todo compromisso é uma estrutura (T-R-I) e é também a condição-chave para que os resultados, individuais e organizacionais, sejam 
alcançados (KOFMAN, 2002, v. II). Para Kofman (2002, v. II), “a capacidade de receber e fazer compromissos é uma das características que definem as pessoas".

Além dos atos de fala básicos e envolvidos e da tríade (T-R-I), outros fatores são necessários para a efetividade das conversas onde compromissos são estruturados, assumidos e executados. Dentre esses fatores, a confiança é parte essencial dessa dinâmica (ECHEVERRÍA, 1998).

De acordo com Echeverría (2002) e Flores (1994), a construção da confiança é realizada a partir de três domínios: sinceridade, competência e responsabilidade. Ao fazer uma promessa, as pessoas se comprometem nesses três domínios (Echeverría, 2002). Nosso desempenho e julgamento público sobre nosso desempenho, em cada um destes domínios é uma das maneiras básicas pelas quais construímos nossa identidade pública (FLORES, 1994).

Promessas são ações linguísticas por excelência da coordenação de ações entre indivíduos. Correspondem a um fenômeno complexo que inclui diversas ações concatenadas denominadas como "ciclo da promessa" ou "ciclo de coordenação de ações” (ECHEVERRÍA, 1998). Ao explorar os elementos básicos (etapas) dos ciclos de coordenação de ações, Flores (2015), afirma que ao fazermos uma promessa, estamos dizendo a outra pessoa que somos capazes de cumprir as condições estabelecidas para o compromisso.

\subsection{Conversas efetivas}

De acordo com Echeverría (1997), em seu núcleo básico a Ontologia da Linguagem tem como foco a interpretação de três termos: seres humanos (são seres linguísticos), linguagem (é generativa) e ação (gera o ser). Com base neste postulado e compreendendo que as organizações realizam suas ações por meio das conversações, a Figura 1, a seguir, apresenta os elementos básicos (etapas) - compostos por atos de fala - que constituem as “conversas para ações" presentes nas organizações (FLORES, 2015, 1996 e 1994; ECHEVERRÍA, 2002 e 1998). 


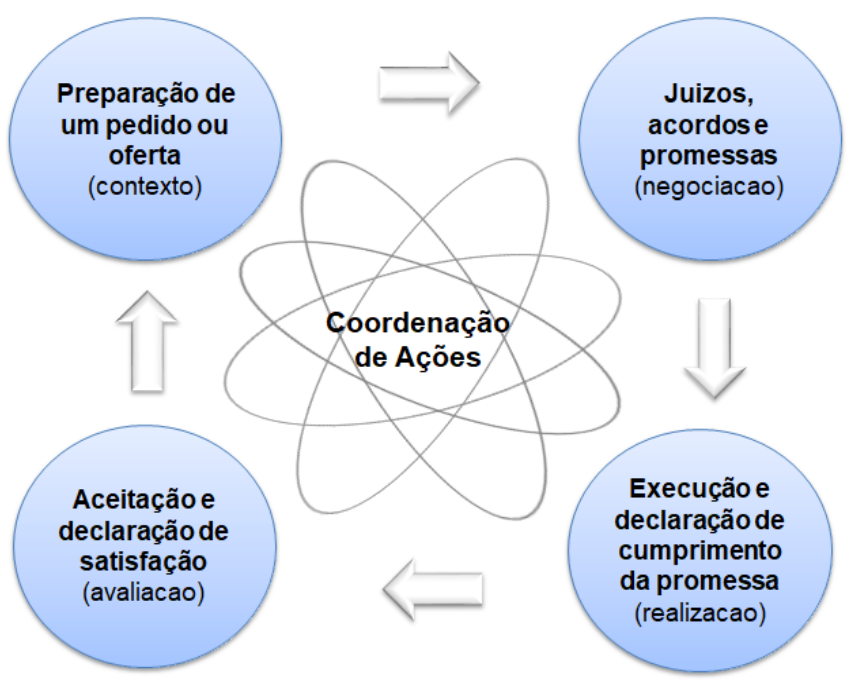

Figura 1: Elementos básicos (etapas) de uma "Conversação para Ação".

Fonte: Elaborado com base em Flores $(2015,1996,1994)$ e Echeverría (2002 e 1998).

Tal como apresentado na seção 2.2, são os vínculos de confiança que possibilitam as coordenações efetivas de ações futuras (KOFMAN, 2002, v. II). E é no centro do ciclo de uma promessa que a confiança e o espaço compartilhado de inquietudes se encontram (ECHEVERRÍA, 1998). Sem a presença destes elementos - confiança e espaço compartilhado de inquietudes - não é possível coordenar ações de forma efetiva. Efetividade, no contexto deste artigo, consiste na obtenção de eficácia (que alcança o objetivo proposto) com eficiência (que se faz com excelência) e sustentabilidade (com condições/capacidade de continuidade). Vale ressaltar que o espaço compartilhado de inquietudes existe dentro de cada cultura e pode variar de organização para organização. Assim, o que é óbvio para um grupo, pode não ser para outro. Daí a necessidade de cuidar das redes de compromissos organizacionais para que os atos de fala (pedidos, ofertas, promessas e declarações) utilizados em um determinado contexto façam sentido para aquela comunidade, no que diz respeito às ações embutidas no que é dito.

Amparado pelos estudos apresentados, este artigo assume o entendimento de que conversas efetivas são aquelas que ao coordenar ações $(\mathrm{T})$ para obter resultados, cuidam dos relacionamentos $(\mathrm{R})$ entre os interlocutores e da identidade (I) dos atores envolvidos na conversação. Assim, uma conversa pode ser compreendida como efetiva quando os três níveis (T-R-I) constitutivos do compromisso assumido são simultaneamente considerados e satisfeitos.

Por outro lado, outra possível caracterização de conversas efetivas está no cumprimento das etapas dos ciclos de coordenação de ações, realizados nos ambientes 
organizacionais. Inicialmente desenvolvido por Flores (1994) e depois trabalhado por Echeverría (1998) e Kofman (2002, v. II) e outros autores, o ciclo de coordenação de ações também denominado ciclo das promessas ou etapas de uma conversação para ação - mostrase um constructo relevante para verificar a efetividade das conversas nas organizações.

\subsection{Modelos mentais}

Considerando que os atos de fala presentes nas conversações correspondem ao núcleo de todo o processo de trabalho realizado nas organizações e que o principal papel do gestor está em cuidar da articulação e ativação de compromissos dentro da rede organizacional, para atingir seus resultados, os líderes devem estar atentos aos esforços para a geração de redes de conversações efetivas (WINOGRAD e FLORES, 1988; FLORES, 2015).

Todavia, conforme Kofman (2002, v. I, p. 263), o grande desafio da teoria objetiva da comunicação é não cair na armadilha de achar que "aquilo que eu digo é o que o outro escuta" e "aquilo que eu escuto é o que o outro diz". Para o autor, "aquilo que cada um escuta está condicionado por seus modelos mentais, pois, entre aquilo que um diz e aquilo que o outro escuta há uma série de filtros que podem gerar brechas entre o sentido do dito e o sentido do escutado" (KOFMAN, 2002, v. I, p. 264).

Como apresentado na Figura 2, são quatro as fontes que determinam a resposta "habitual" que damos a certas circunstâncias, programadas no nosso modelo mental: biologia, linguagem, cultura e história (KOFMAN, 2002, v. I).

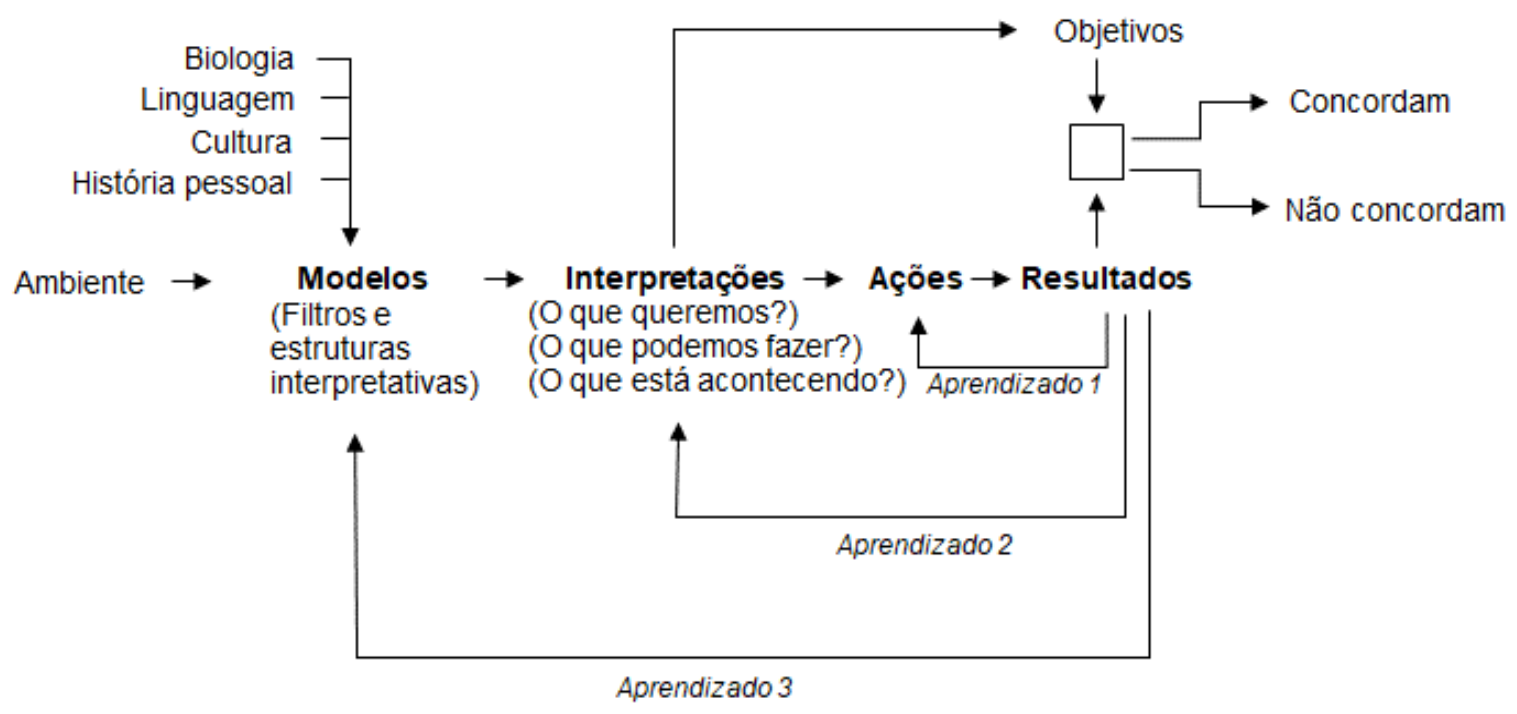

Figura 2: Mapa do Observador, Ação e Resultado.

Fonte: Kofman (2002, v. I, p. 316). 
A partir do "Mapa do Observador, Ação e Resultado" apresentado por Kofman (2002, v. I), Lucena Filho (2014) coloca que as conversas, enquanto instrumentos de atuação humana, atuam nos três níveis: das ações, das interpretações e dos modelos mentais. Sendo que para cada um desses níveis há um nível de aprendizagem (e de complexidade) correspondente, ou seja: aprendizagem de $1^{\mathrm{a}}, 2^{\mathrm{a}}$ e $3^{\mathrm{a}}$ ordem.

Ainda de acordo com Lucena Filho (2014, p. 6), “em última instância, as conversas visam transformar o modo de ser (modelos mentais e interpretações) do Observador. Para isso se utilizam de técnicas e ferramentas conversacionais. Sua efetividade pressupõe uma relação ética baseada no respeito pela: legitimidade, autonomia, liberdade e diferença do outro".

\subsection{O falar e o escutar efetivo}

A comunicação humana possui duas facetas, o "falar" e o "escutar". O falar efetivo somente é possível se for seguido de um escutar efetivo, isto porque é o escutar efetivo que confere sentido ao que é dito. Escutar é o fator fundamental da linguagem. "Falamos para sermos escutados" (ECHEVERRÍA, 1997, p. 81).

Uma contribuição que vem ao encontro do que é apresentado por Lucena Filho (2014; 2010) sobre o uso de técnicas e ferramentas conversacionais, é encontrada em Kofman (2002, v. II) que aborda as conversas sob dois ângulos: o expor e o indagar. De acordo com o autor, o indagar não costuma estar presente nas conversações com a mesma frequência que o expor. Nem sempre as pessoas estão abertas a "escutar" o que o outro tem a dizer. E, ao "falar", é comum observar atitudes de imposição de ideias ou opiniões, assim como também é comum, perceber uma certa competitividade em boa parte das conversas realizadas nas organizações. Kofman (2002, v. II) denomina esses fenômenos como o expor e o indagar improdutivos.

No sentido contrário, o expor produtivo "é uma forma de abrir aos outros os nossos raciocínios, para ajudá-los a entender porque pensamos o que pensamos" (KOFMAN, 2002, v. II, p. 98). O indagar produtivo "é uma maneira de descobrir os raciocínios dos outros e ajudá-los a expor não só o que pensam como também por que pensam aquilo que pensam”. (KOFMAN, 2002, v. II, p. 102).

Com relação ao escutar efetivo, o desafio é ainda maior, pois é ele que dirige todo o processo de comunicação. O escutar efetivo está na capacidade de perceber atos de fala ilocucionários presentes nos atos de fala locucionários. Para isso, são necessárias determinadas distinções. De acordo com Maturana e Varela (2001), o fenômeno da comunicação não depende do que se entrega, mas sim, do que se passa com o que se recebe. 
Logo, o fator decisivo na equação do escutar é a interpretação. A compreensão das fontes que determinam os modelos mentais dos observadores é um dos caminhos que permitem fornecer distinções que contribuem para o processo de interpretação.

O escutar, o expor e o indagar fazem parte do universo de competências conversacionais. Ao capacitar as pessoas a usar conscientemente as palavras para articular compromissos e invocar uma coordenação efetiva de suas ações, é possível reduzir os malentendidos e os erros que impedem que muitas organizações percebam seu potencial (FLORES, 2015).

Nesse contexto, considerando que os talentos básicos e as vivências contribuem para novas formas de "ser" e "fazer", este estudo acrescenta um quinto nível (experiência) aos quatro níveis (conhecimentos, habilidades, atitudes e valores) nos quais, de acordo com Lucena Filho (2010), as competências conversacionais se manifestam. Dessa forma, complementando Lucena Filho (2010), este artigo compreende competência conversacional como a capacidade de, conversando, mobilizar, articular e colocar em ação, de forma sustentável, conhecimentos, habilidades, atitudes, valores e experiências necessárias para o desempenho eficiente e eficaz de atividades requeridas no trabalho e na vida.

\section{DISTINÇÕES CONVERSACIONAIS APLICADAS NO CONTEXTO DAS REDAÇÕES}

\subsection{As redações jornalísticas}

A configuração das redações, para além da disposição de um ambiente físico, é essencialmente composta por dinâmicas e fluxos interpessoais que levam ao "produto notícia”. Elementos técnicos e tecnológicos (inovação e mudança nos recursos, nas ferramentas, nas atividades e nos processos) permeiam e influenciam diretamente o que acontece nesse ambiente, afetando as competências conversacionais dos envolvidos no processo de produção da notícia e, consequentemente, a gestão da informação e do conhecimento organizacional.

As rotinas produtivas das redações, que inicialmente seguiam um fluxo mais horizontal, com reunião de pauta, apuração, edição, impressão e distribuição foram gradativamente alteradas e hoje pode-se dizer que apresentam processos sobrepostos e que podem ser modificados a qualquer momento, a exemplo da constante possibilidade de revisão e alteração de conteúdo nos jornais online. A premissa apontada por Traquina (1993), de que 
as rotinas permitem que os profissionais transformem os acontecimentos diários em notícia (TRAQUINA, 1993), encurtando processos de tomada de decisão e agilizando o processo ainda é válida, apesar das transformações provocadas pelas tecnologias.

Diante desse cenário de alterações, os ambientes de redações jornalísticas têm mostrado crescente preocupação, não apenas com a qualidade da produção de informação nos diversos suportes e tecnologias, mas também em relação à convergência no processo de produção e disseminação do conteúdo, considerando as necessidades e especificidades dos vários perfis de informação do usuário. As iniciativas de convergência nas redações, nas formas de produção e no conteúdo já são realidades visíveis, como apontam Santos et al. $(2019)^{2}$.

Para compreender o conceito de convergência aplicado ao jornalismo, partimos de Henry Jenkins (2009), que utiliza o termo convergência midiática, para explicar o movimento ao qual os meios aderiram para se adaptar à internet e assim distribuir seus produtos. Os motivadores principais da convergência são as mudanças tecnológicas e a digitalização dos processos. Desse modo, a convergência funciona como resposta aos novos processos comunicacionais surgidos com as Tecnologias da Informação e da Comunicação (TIC) e passa a afetar diversas dimensões da produção informativa (SILVA; PEREIRA; RIBEIRO, 2013, p. 51), incluindo a forma como os usuários e profissionais envolvidos no processo de produção da notícia coordenam as ações entre si.

O contexto multifacetado da convergência impede, contudo, uma definição unânime, como defendem Avilés, Kaltenbrunner e Meier (2014) ao revisitar o conceito. Para os autores a convergência aparece como um fenômeno que influencia o sistema de mídia, moldando diferentes dimensões da comunicação. A convergência das redações, embora seja um processo em desenvolvimento, tem provocado transformações no processo de produção da notícia. Como as mudanças impactam o fluxo de trabalho dos profissionais, tais impactos se refletem também nos processos de coordenação de ações, nos relacionamentos entre os interlocutores e na identidade dos atores envolvidos na conversação, afetando a tríade T-R-I. Por exemplo, a priorização de conteúdos online por jornais impressos é um dos movimentos verificados (LENZI, 2018) que atuam diretamente sobre a tríade. A redação, que antes era regrada por um ritmo mais lento, passa a ser pressionada a adentrar num ciclo de inovação nas

\footnotetext{
2 Os autores utilizaram os mesmos dados primários do Projeto MDM para fazer um estudo comparativo das redações jornalísticas em contexto de convergência no Brasil, na Costa Rica e na Inglaterra.
} 
empresas jornalísticas, no qual a velocidade de publicação do conteúdo também se constitui como elemento determinante. Portanto, se considerarmos que os atos de fala são o núcleo central do processo produtivo do jornalismo e que é necessária articulação e ativação de compromissos dentro da redação para que o jornal funcione, automaticamente denota-se uma maior necessidade de atenção e esforços para que redes de conversações efetivas sejam criadas e mantidas nesses ambientes a fim de se obter melhores resultados ou resultados satisfatórios.

Nesse aspecto, Lenzi (2018) demonstra que dentro do cenário de convergência no contexto contemporâneo internacional das redações tem sido reforçada a prática de coleta e formatação do conteúdo jornalístico feita por um mesmo grupo profissional integrado e o empacotamento dos dados de acordo com cada plataforma, sendo a edição realizada por equipes distintas. Assim, mais uma vez demonstra-se a necessidade de ações coordenadas e conversadas.

Além disso, os processos de trabalho e produção incorporam cada vez mais a participação dos consumidores de informação e a demanda por novos produtos, modificando os fluxos de trabalho e as redes de compromissos, em seus aspectos qualitativos, quantitativos e logísticos. Ultrapassada a ideia de um leitor meramente receptivo, presencia-se hoje o leitor produtor de conteúdo, a audiência participativa (TÁRCIA, 2007). A interação por parte do público acaba impactando na rotina dos profissionais, requerendo estratégias tanto tecnológicas quanto de políticas editoriais para lidar com demandas, sugestões e rotina interativa. As políticas editoriais são um conjunto de regras centrais da organização jornalística, definindo padrões e comportamentos dos profissionais em relação aos diversos aspectos da produção, caracterizando-se como um guia que serve de modelo aos líderes ou no caso das redações aos editores, para auxiliar na coordenação das equipes e no alcance do resultado final que é o jornal. Entretanto, com as mudanças rápidas e o cenário ainda desconhecido, os acordos e as conversas internas ganham relevância ainda maior, sendo decisivos para que haja o atendimento das necessidades impostas pelas novas mídias e a manutenção do processo produtivo da redação.

As plataformas de mídias sociais, por exemplo, foram progressivamente adotadas nas redações ao longo dos anos e as comunidades on-line tornaram-se parte integrante do processo de produção de notícias. Como destacam Heravi e Harrower "Os jornalistas monitoram as mídias sociais em busca de notícias e conteúdo, usam-nas para encontrar fontes e testemunhas oculares, e aproveitam seu amplo alcance para obter perspectivas variadas 
sobre eventos interessantes" (2016, p. 1195). Um exemplo de redes que geram, repercutem e impactam o conteúdo jornalístico é o Twitter. Conforme exemplificam Lasorsa, Lewis e Holton (2012, p.22) "Social network sites such as Twitter have helped the audience to become active in the news-creation process [...], where messages move back and forth and where users have a chance to interact with information".

Alinhado a esse processo de mudança, alguns aspectos observados nas entrevistas realizadas pela equipe do Projeto Mídia Digital Multimodal (MDM), apresentados a seguir, foram considerados de especial relevância para este estudo. Entre elas, as mudanças relacionadas à inserção dos consumidores das notícias nas cadeias de compromissos responsáveis pela produção da notícia - antes compostas apenas por profissionais inseridos em ambientes de redações jornalísticas, as frequentes mudanças geradas pelas novas TIC e, em particular, a possibilidade de concordar e assumir compromissos com pessoas de diferentes lugares e culturas.

\subsection{Conversas efetivas em redações jornalísticas}

Com base nas distinções apresentadas nas seções anteriores, conversas efetivas em ambientes de redações jornalísticas são aquelas que ao cuidar da coordenação das tarefas (T) para obter os resultados desejados, também cuidam das relações (R) de confiança e das identidades (I) das pessoas envolvidas no processo de produção da notícia. Além disso, dado que redações jornalísticas são redes de compromissos organizacionais e, como tais, constituem e cumprem promessas para alcançar seus objetivos, a efetividade dos ciclos de coordenação de ações realizados nos ambientes de redações, podem fornecer informações significativas sobre a efetividade das conversas desenvolvidas por suas equipes.

Vale observar que, ao utilizar a tríade (T-R-I) e o ciclo de coordenação de ações como constructos teóricos para análise dos dados secundários apresentados adiante, são utilizadas distinções sobre modelos mentais, falar e escutar efetivo, confiança, espaço compartilhado de inquietude e outros fundamentos aplicados aos ambientes de redações jornalística.

Para ajudar a ilustrar a narrativa sobre a efetividade das conversações em ambientes de redações jornalísticas a Figura 3, a seguir, apresenta as etapas de uma conversa para coordenação de ações (Figura 2), onde os níveis T-R-I dos compromissos são trabalhados, a partir de juízos baseados na confiança, com o objetivo de satisfazer certas condições futuras no caso das redações, a produção de notícias qualificadas e no tempo adequado. 


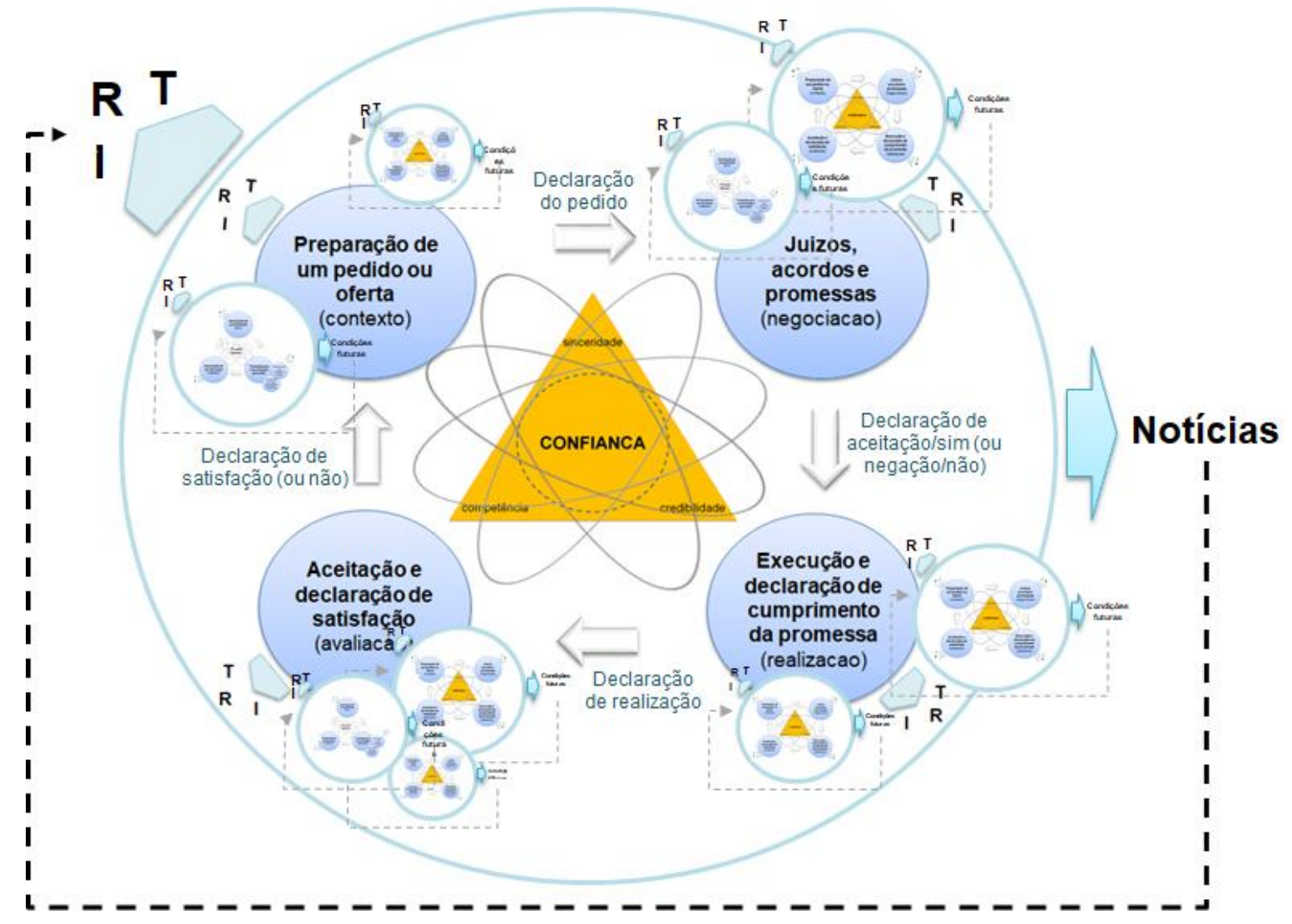

Figura 3: Ciclo de coordenação de ações em ambientes de redações jornalísticas.

Fonte: Elaborado com base em Flores (2015, 1996, 1994), Echeverría (2002, 1998, 1997) e Kofman (2002).

Tal como ilustrado, cada uma das etapas do ciclo de coordenação de ações trata de tarefas (T) que são desenvolvidas, por meio de relacionamentos (R), dentro da identidade (I) dos envolvidos, portanto, da tríade (T-R-I).

A Figura 3 chama atenção para a existência de várias conversas dentro de uma conversa maior ou de vários compromissos dentro de um compromisso mais amplo. $\mathrm{O}$ resultado de cada "pequeno" compromisso afeta os demais compromissos acordados na rede de conversas onde as ações estão sendo coordenadas. Afetando, portanto, o compromisso "maior" em que todos estão envolvidos.

Nos ambientes de redações jornalísticas isso é facilmente observado quando, por exemplo, a publicação de uma única notícia depende de diversas articulações de ações entre diferentes equipes de fotografia, redação e disponibilização de conteúdo em múltiplas mídias. Tudo acontecendo ao mesmo tempo e com forte dependência entre a entrega de um compromisso e o início, continuação e/ou conclusão de outro. 
Este estudo considera que os níveis T-R-I dos compromissos assumidos pelas redes presentes nas redações jornalísticas, geram resultados e são impactados por estes, proporcionando sua própria evolução. Dessa forma, o resultado é a interação como um todo, onde ao produzir notícia (tarefa), a rede se reconfigura (relacionamentos) e as identidades (integridade e dignidade) dos profissionais envolvidos no compromisso também mudam. Os níveis T-R-I são absolutamente complementares e interdependentes; ou seja, precisam ser congruentes uns com os outros.

\subsection{Dados primários}

Entre abril de 2015 e maio de 2017, pesquisadores do Projeto MDM realizaram um conjunto de visitas às redações jornalísticas dos seguintes veículos: BBC (Inglaterra), Correio Braziliense (Brasil), La Nación (Costa Rica), O Globo (Brasil) e Reuters (Inglaterra). Durante essas visitas, foram entrevistados editores, subeditores, repórteres, chefes de redação e representantes das áreas de fotografia, design e tecnologia da informação dos jornais visitados.

Conforme apresentado por Oliveira (2017), as visitas realizadas compreenderam participação de reuniões de pauta; observação das dinâmicas de trabalho dos jornais; conhecimento dos processos de recebimento e averiguação de fatos; levantamento de parte dos softwares utilizados etc.. Os dados primários a que se refere esse artigo correspondem às gravações das entrevistas realizadas. Os dados secundários correspondem aos trechos extraídos dos dados primários.

Inserido no campo da Ciência da Informação, este artigo busca explorar os aspectos teóricos relacionados às competências conversacionais no processo de produção da notícia, apresentados nas seções anteriores. Para isso, além de pesquisadas referências sobre conversas efetivas, na perspectiva da Ontologia da Linguagem, foram extraídos trechos das gravações das entrevistas que tratavam de algum nível de coordenação de ações entre as equipes das redações visitadas. Posteriormente a essa seleção de dados primários e extração de dados secundários, a partir da fundamentação teórica apresentada, foi realizada a análise dos dados descrita na seção 5 .

Conforme revelaram os dados, processos de produção da notícia são, fundamentalmente, processos conversacionais. Além disso, cada ambiente funciona de acordo com a sua cultura. Notícias geradas em diferentes redações podem ser similares, porém, as redes de compromissos que as geram se comportam de formas diferentes. Daí a relevância de 
um instrumento de análise capaz de fornecer subsídios para a ampliação das competências conversacionais das redes de compromissos envolvidas no processo de produção da notícia.

\section{MÉTODOS E PROCEDIMENTOS}

Tendo como base a Ontologia da Linguagem - que compreende que os comportamentos são significativamente impactados pela linguagem, inicialmente este estudo caracterizou-se como uma pesquisa descritiva, aplicada e exploratória. Todavia, após a aplicação do primeiro instrumento de análise, ao focalizar os dados e o campo de estudo e desenvolver um segundo instrumento de análise de dados, a pesquisa passou a ser considerada também metodológica, tendo como base a Teoria Fundamentada nos Dados (TFD).

Desenvolvida por Glaser e Strauss, a TFD utiliza procedimentos para desenvolver indutivamente uma teoria derivada dos dados. Sua premissa básica é a de que "tudo é informação" (BROWN, 2013). Segundo Gasque (2007, p. 90), na TFD, "o pesquisador constrói uma teoria a partir da observação específica do fenômeno". De acordo com a autora, isso envolve um processo de amostragem teórica (estratégia de definição gradual da amostra, sensibilidade teórica do pesquisador e controle pela teoria em formação), codificação (conceituação dos dados, comparação entre fenômenos, casos e conceitos e fundamentação de uma teoria) e redação da teoria (relações entre as categorias, apresentação das descobertas e descrição da teoria).

\subsection{Primeiro instrumento de análise}

$\mathrm{O}$ primeiro instrumento de análise foi dividido em duas etapas. A etapa I referiu-se à seleção de trechos (dados secundários) das gravações das entrevistas (dados primários) que apresentavam algum nível de coordenação de ações e realização de compromissos pelas equipes responsáveis pela produção da notícia. A etapa II correspondeu a um questionário, respondido com base nos trechos (dados secundários) oriundos da etapa I, com perguntas genéricas e específicas sobre os fundamentos teóricos aqui expostos, baseadas no trabalho de Ávila et al. (2017) que, por sua vez, baseou-se em Andrade (2009) e Braga (2007).

Nesta etapa II, as perguntas genéricas, distribuídas em seis itens, procuraram levantar aspectos relacionados ao falar e escutar efetivo, confiança, compartilhamento de inquietudes e outros pontos relacionados nos fundamentos teóricos. As perguntas específicas basearam-se na tríade (T-R-I), no ciclo de coordenação de ações e no conceito de conversas efetivas em ambientes de redações jornalísticas apresentado. 


\subsection{Segundo instrumento de análise}

O segundo instrumento de análise constitui-se na Matriz de Sentidos, apresentada na seção 5, que propõe uma relação entre as características dominantes, presentes no processo de produção da notícia, das redações visitadas (características observadas nos dados secundários oriundos da etapa I do primeiro instrumento de análise) e as variáveis dos fundamentos teóricos investigados.

Tanto a lista de perguntas genéricas e específicas, presente na etapa II do primeiro instrumento de análise, quanto a estrutura da Matriz de Sentidos que corresponde ao segundo instrumento de análise, aplicadas neste estudo, representam roteiros que podem ser utilizados para analisar e orientar as conversas em reuniões de redações jornalísticas, buscando-se a sua efetividade (eficácia, eficiência e sustentabilidade) ${ }^{3}$.

\section{ANÁLISE E RESULTADOS}

Conforme exposto na seção 3, este trabalho observou as gravações de entrevistas não estruturadas, realizadas junto aos profissionais de jornalismo das cinco redações visitadas. Como as entrevistas trataram de assuntos diversos, de interesse do Projeto MDM e, por isso, não contemplaram perguntas diretamente relacionadas a conversas efetivas nos ambientes de redações jornalísticas, a aplicação do primeiro instrumento de análise foi precedida pelas seguintes tarefas:

a. transcrição parcial (com foco no que é relevante para a análise) das gravações das entrevistas não estruturadas (dados primários) em formato de textos ou slides;

b. organização do conteúdo transcrito, de acordo com os assuntos discutidos durante as entrevistas, buscando identificar padrões de temas tratados.

Após a execução dessas tarefas, o primeiro instrumento de análise foi então aplicado. Essa aplicação foi realizada em duas etapas. A etapa I que utilizou os dados primários (gravações das entrevistas) para gerar os dados secundários (trechos que apresentavam algum nível de coordenação de ações e realização de compromissos relacionados à produção da notícia) e a etapa II (posteriormente descartada) que utilizou os dados secundários (trechos selecionados na etapa I) para responder ao questionário e gerar gráficos e análises a partir das

\footnotetext{
${ }^{3}$ Essas possibilidades são apresentadas na seção 6 que trata de trabalhos futuros.
} 
respostas obtidas (que se mostraram inconclusivas e por isso não foram aproveitadas neste estudo).

A utilização de dados primários, colhidos em pesquisa anterior ao estudo aqui apresentado, levantados por observadores diferentes dos autores deste artigo e com preocupações diferentes das aqui exploradas, não permitiu a obtenção de respostas úteis ao roteiro de perguntas que compunha a etapa II do primeiro instrumento de análise. Dessa forma, percebeu-se que não seria possível investigar com algum nível de profundidade as conversações em curso nas redações à luz das gravações das entrevistas realizadas pela equipe do Projeto MDM. Estes dados primários demonstraram que não havia singularidade, roteiro ou pauta estruturante que revelassem um certo grau de homogeneidade nas gravações. Ademais, não foi encontrada evidência de que existia um método por trás das entrevistas. $\mathrm{O}$ que explica a diversidade dos objetos encontrados nos dados primários.

Entretanto, a tentativa de responder as perguntas genéricas e específicas da etapa II do primeiro instrumento de análise, embora não tenha atendido ao objetivo pretendido, demonstrou, a possibilidade de relacionar as características percebidas como dominantes nas redações com os fundamentos teóricos investigados.

Dessa forma, com base na TFD, foi desenvolvido e aplicado um segundo instrumento, a Matriz de Sentidos, cujo preenchimento foi fundamentado nas "afirmações de suporte"4 extraídas e interpretadas dos dados secundários, dentre elas: “Temos reuniões todos os dias. Antes da reunião geral com todos os editores há uma reunião de cada editor com seus repórteres. O surgimento e a popularização das mídias sociais geram impactos profundos na prática jornalística e na elaboração de novos modelos de negócio na indústria informativa.” (La Nación); “É sempre muito bom tomar um café e conversar porque você acaba construindo relacionamentos. O público muitas vezes ouvirá uma história em outra fonte e então virá para a BBC para verificar se é verdade. Temos sites em árabe, japonês, indiano e em outros idiomas. O esforço internacional tem muitos aspectos diferentes, dentre eles, a tradução. Nossa filosofia editorial é que é melhor chegar atrasado do que estar errado. Cada vez mais o

\footnotetext{
${ }^{4}$ O termo "afirmações" na Ontologia da Linguagem (Echeverria, 1997, p. 42) denota um "ato linguístico" com características muito próprias; em particular, traz consigo a necessidade imperativa de que o que é dito seja passível de ser acompanhado por uma (ou mais) evidência(s) factual, inequivocamente comprovável! No caso em foco, os trechos destacados das entrevistas realizadas estão sendo referenciadas como "afirmações de suporte" porque as entrevistas foram gravadas e podem, a qualquer momento, serem utilizadas como suporte para evidenciar a manifestação das "locuções" enunciadas pelos interlocutores participantes das entrevistas! E aqui é importante, não confundir "locuções" com "ilocuções”. (ECHEVERRÍA, 1997, p. 86)
} 
público está consumindo notícias em dispositivos como smartphone." (BBC); "Com essas multi habilidades, as pessoas estão aproveitando melhor os " $\mathrm{N}$ " tipos de mídias e explorando melhor as oportunidades, inclusive em momentos do dia a dia em que surgem oportunidades. Temos profissionais muito bons de todas as diferentes disciplinas, eles estão em um momento de grande transformação. Pessoas de uma área estão procurando aprender sobre outras áreas. As habilidades precisam fazer sentido para o profissional e para a organização. Procuramos fazer com que as pessoas se conheçam, trabalhem juntas e cooperem entre si.” (Reuters); “Tendo em vista as mudanças na profissão do jornalista, é importante que o repórter seja multimídia e esteja cada vez mais preparado e atualizado nos diferentes assuntos." (Correio). “O repórter não recebe os dados passivamente e nem é um mero mediador da informação. Ele precisa de competências investigativa, analítica e comunicativa." (O Globo).

A Matriz a seguir representa um processo de análise ontológica de sentido e apresenta uma lista das principais características dominantes e comuns às redações visitadas, relacionando-as às principais variáveis dos fundamentos teóricos investigados. 
Matriz de Sentidos

\begin{tabular}{|c|c|c|c|c|c|}
\hline $\begin{array}{l}\text { Características } \\
\text { dominantes }\end{array}$ & $\begin{array}{c}\text { Ciclo de Coordenação de Ações } \\
\text { (Princípios e Diretrizes, Preparação, } \\
\text { Execução e Reflexão) }\end{array}$ & $\begin{array}{c}\text { Tríade } \\
\text { (Tarefa, Relacionamento e } \\
\text { Identidade) } \\
\end{array}$ & $\begin{array}{c}\text { Modelos Mentais } \\
\text { (Aprendizados de } 1^{\mathrm{a}}, 2^{\mathrm{a}} \text { e } 3^{\mathrm{a}} \text { Ordem) }\end{array}$ & Falar produtivo & Escutar efetivo \\
\hline $\begin{array}{l}\text { Realização de } \\
\text { reuniões para } \\
\text { combinar as pautas } \\
\text { de notícias. Em } \\
\text { alguns casos, mais } \\
\text { de uma vez por dia. }\end{array}$ & $\begin{array}{l}\text { Reuniões de pauta são exemplos de } \\
\text { espaços para alinhamento sobre os } \\
\text { princípios e diretrizes relacionados aos } \\
\text { compromissos que foram ou que serão } \\
\text { assumidos, preparação das atividades } \\
\text { que darão conta dos compromissos, } \\
\text { monitoramento do que é executado e } \\
\text { reflexões sobre o que já foi realizado. } \\
\text { O cuidado com as etapas que fazem } \\
\text { parte de um ciclo de coordenação de } \\
\text { ações contribui para a produtividade das } \\
\text { reuniões e a obtenção de resultados. }\end{array}$ & $\begin{array}{l}\text { O entendimento da tarefa a ser } \\
\text { executada, a qualidade dos } \\
\text { relacionamentos entre os } \\
\text { participantes e o alinhamento à } \\
\text { identidade dos envolvidos nas } \\
\text { atividades impactam } \\
\text { diretamente na produtividade e } \\
\text { alcance dos compromissos } \\
\text { acordados nas reuniões. }\end{array}$ & $\begin{array}{l}\text { - Reuniões de pauta são espaços de } \\
\text { aprendizagem à medida que permitem aos } \\
\text { participantes avaliarem e revisitarem suas } \\
\text { possibilidades de ação, de interpretação e } \\
\text { os modelos mentais que as orientam. } \\
\text { - Essa permissão para aprender impacta } \\
\text { diretamente nos compromissos acordados } \\
\text { durante as reuniões à medida que } \\
\text { incentivam o desenvolvimento e a } \\
\text { criatividade das equipes, em função de } \\
\text { resultados positivos para as redações. }\end{array}$ & $\begin{array}{l}\text { - Reuniões de pauta são espaços para } \\
\text { o exercício da exposição e da } \\
\text { indagação produtiva. } \\
\text { - A coragem e disponibilidade das } \\
\text { pessoas para esclarecer e } \\
\text { compartilhar suas interpretações } \\
\text { sobre comportamentos e resultados } \\
\text { relacionados aos compromissos } \\
\text { contribuem para a eficiência e } \\
\text { eficácia das ações acordadas. }\end{array}$ & $\begin{array}{l}\text {-O adequado entendimento do passo a } \\
\text { passo necessário para coordenar ações, } \\
\text { normalmente discutidas nas reuniões } \\
\text { de pauta, o que inclui a compreensão } \\
\text { da tarefa a ser executada, o cuidado } \\
\text { com os relacionamentos e as } \\
\text { identidades dos envolvidos, depende } \\
\text { diretamente da capacidade de escuta } \\
\text { dos participantes das reuniões. } \\
\text { Impactando no aproveitamento do } \\
\text { tempo das reuniões e das competências } \\
\text { das equipes, e na obtenção de } \\
\text { resultados }\end{array}$ \\
\hline $\begin{array}{l}\text { Dependência de } \\
\text { atores (internos e } \\
\text { externos à redação) } \\
\text { com diferentes } \\
\text { competências para } \\
\text { cumprir as tarefas. }\end{array}$ & $\begin{array}{l}\text { O cuidado com as etapas que fazem } \\
\text { parte de um ciclo de coordenação de } \\
\text { ações contribui para a articulação das } \\
\text { tarefas, planejamento de prazos, custos } \\
\text { e responsabilidades, considerando as } \\
\text { diferentes competências dos atores } \\
\text { (internos e externos) envolvidos com as } \\
\text { atividades. }\end{array}$ & $\begin{array}{l}\text { Independentemente da } \\
\text { localização (interna ou externa à } \\
\text { redação), meio de comunicação } \\
\text { (presencial/fisico ou à } \\
\text { distância/virtual) no qual os } \\
\text { atores estão trabalhando, o nível } \\
\text { relacionamento de um } \\
\text { compromisso deve ser cuidada } \\
\text { para que as identidades dos } \\
\text { diferentes perfis de profissionais } \\
\text { sejam respeitadas e as tarefas } \\
\text { sejam cumpridas. }\end{array}$ & $\begin{array}{l}\text { - Modelos mentais são formados por filtros } \\
\text { e estruturas interpretativas, nos quais } \\
\text { diferentes observadores, constroem } \\
\text { diferentes realidades. } \\
\text { - O reconhecimento da existência desses } \\
\text { filtros contribui para o entendimento entre } \\
\text { as equipes e, consequentemente, para a } \\
\text { realização dos desafios presentes nas } \\
\text { redações jornalisticas, à medida que o } \\
\text { processo de produção da notícia é } \\
\text { realizado por diferentes } \\
\text { atores(observadores) com suas diferentes } \\
\text { biologias, linguagens, culturas e histórias. }\end{array}$ & $\begin{array}{l}\text { - A exposição a partir das inquietudes } \\
\text { de quem fala e a indagação para que } \\
\text { o outro revele as suas inquietudes } \\
\text { contribuem para a compreensão do } \\
\text { que é dito e, consequentemente, para } \\
\text { efetividade dos compromissos que } \\
\text { envolvem diferentes atores com } \\
\text { diferentes competências. }\end{array}$ & $\begin{array}{l}\text { - Compromissos desenvolvidos por meio } \\
\text { de parcerias exigem capacidade de } \\
\text { escuta das partes envolvidas. } \\
\text { - Escutas equivocadas provocam } \\
\text { desentendimentos entre profissionais } \\
\text { que dependem uns dos outros e, } \\
\text { consequentemente, geram desgastes, } \\
\text { retrabalho, perda de tempo e dinheiro, } \\
\text { além de frustrações e outras } \\
\text { consequências. }\end{array}$ \\
\hline $\begin{array}{l}\text { Necessidade de } \\
\text { apresentar resultado } \\
\text { diariamente. }\end{array}$ & $\begin{array}{l}\text { - As equipes precisam ter a capacidade de } \\
\text { se comprometerem e se comportarem de } \\
\text { forma a alcançarem resultados diários. } \\
\text { Para isso, é fundamental saberem o que } \\
\text { deve ser feito, por quem, quando e } \\
\text { como. }\end{array}$ & $\begin{array}{l}\text { A produção diária de notícias } \\
\text { demonstra a necessidade de } \\
\text { cumprimento de tarefas } \\
\text { diariamente pelas equipes. }\end{array}$ & $\begin{array}{l}\text { - A compreensão dos diferentes níveis de } \\
\text { aprendizagem e do impacto dos modelos } \\
\text { mentais nas decisões e ações das equipes } \\
\text { responsáveis pela produção da notícia, } \\
\text { contribui para torna-las mais conhecedoras } \\
\text { das suas potencialidades, dificuldades e, } \\
\text { sobretudo, do que as leva a isso. } \\
\text { - Essa consciência serve de base para o } \\
\text { desenvolvimento de ações - a partir de } \\
\text { interpretações, orientadas por modelos } \\
\text { mentais - mais assertivas e coerentes com } \\
\text { os resultados almejados pelos } \\
\text { profissionais da informação, pelas } \\
\text { redações jornalísticas e seus usuários. }\end{array}$ & $\begin{array}{l}\text { - A produção diária de notícias } \\
\text { evidencia a necessidade de } \\
\text { constantes entendimentos a respeito } \\
\text { das tarefas que devem ser entregues } \\
\text { pelas equipes. } \\
\text { - Esses entendimentos acontecem por } \\
\text { meio das conversas que são } \\
\text { impactadas negativa ou } \\
\text { positivamente pela capacidade de } \\
\text { "fala" das equipes. }\end{array}$ & $\begin{array}{l}\text { - A produção diária de notícias evidencia } \\
\text { a necessidade de constantes } \\
\text { entendimentos a respeito das tarefas } \\
\text { que devem ser entregues pelas equipes. } \\
\text { - Esses entendimentos acontecem por } \\
\text { meio das conversas que são } \\
\text { impactadas negativa ou positivamente } \\
\text { pela capacidade de "escuta" das } \\
\text { equipes. }\end{array}$ \\
\hline
\end{tabular}




\begin{tabular}{|c|c|c|c|c|c|}
\hline $\begin{array}{l}\text { Necessidade de } \\
\text { diálogo constante } \\
\text { entre os atores para } \\
\text { a realização do } \\
\text { processo de } \\
\text { produção da notícia } \\
\text { (busca, apuração, } \\
\text { fotografia, edição e } \\
\text { publicação). }\end{array}$ & $\begin{array}{l}\text { - A clareza com relação aos princípios e } \\
\text { diretrizes que orientam os } \\
\text { compromissos, o exercício de } \\
\text { preparação das atividades, o } \\
\text { monitoramento do que é executado e a } \\
\text { possibilidade de reflexões a respeito dos } \\
\text { trabalhos, contribui para o diálogo } \\
\text { efetivo entre as equipes responsáveis } \\
\text { pela produção da notícia. } \\
\text { A existência de confiança entre os } \\
\text { membros das equipes é a base para } \\
\text { coordenações de ações efetivas }\end{array}$ & $\begin{array}{l}\text { A capacidade de as pessoas } \\
\text { aproveitarem suas próprias } \\
\text { competências de forma } \\
\text { autêntica, respeitando sua } \\
\text { identidade, contribui para } \\
\text { produtividade do } \\
\text { relacionamento entre as partes e } \\
\text { para a execução das tarefas a } \\
\text { serem cumpridas. }\end{array}$ & $\begin{array}{l}\text { - As conversas transformam o modo de ser } \\
\text { (modelos mentais com seus filtros e } \\
\text { estruturas interpretativas) dos indivíduos } \\
\text { (observadores). } \\
\text { - Considerando que é por meio das } \\
\text { conversas que os compromissos de uma } \\
\text { equipe ou organização são realizados, } \\
\text { investimentos nos diferentes níveis de } \\
\text { aprendizagem dos profissionais da } \\
\text { informação e, consequentemente, da } \\
\text { própria redação jornalística, contribuem } \\
\text { para eficiência, eficácia e efetividade do } \\
\text { processo de produção da notícia. }\end{array}$ & $\begin{array}{l}\text { - A capacidade de fazer pedidos e } \\
\text { ofertas, sabendo da possibilidade de } \\
\text { recusa, assim com a liberdade de } \\
\text { indagar, procurando descobrir os } \\
\text { raciocínios dos outros, contribuem } \\
\text { para o diálogo produtivo e, } \\
\text { consequentemente, para a } \\
\text { articulação de ações entre os } \\
\text { responsáveis pela produção da } \\
\text { notícia. }\end{array}$ & $\begin{array}{l}\text { - A abertura para aceitar uma recusa de } \\
\text { um pedido não como uma rejeição ou } \\
\text { uma falta de comprometimento, mas } \\
\text { como uma ação de sinceridade e } \\
\text { responsabilidade contribuem para o } \\
\text { diálogo produtivo e, } \\
\text { consequentemente, para a articulação } \\
\text { de ações entre os responsáveis pela } \\
\text { produção da notícia. }\end{array}$ \\
\hline $\begin{array}{l}\text { Necessidade de } \\
\text { abertura para o } \\
\text { novo, à medida que } \\
\text { ideias, informaçôes, } \\
\text { criticas e soluçôes } \\
\text { podem vir de } \\
\text { qualquer parte e a } \\
\text { qualquer momento } \\
\text { - inclusive dos } \\
\text { usuários finais da } \\
\text { informação, dentre } \\
\text { eles, leitores, } \\
\text { ouvintes e } \\
\text { telespectadores. }\end{array}$ & $\begin{array}{l}\text { A realização de } \\
\text { compromissos, por meio de ciclos de } \\
\text { coordenação de ações facilita o } \\
\text { acolhimento, análise, incorporação (ou } \\
\text { não) e feedbacks a ideias, críticas e } \\
\text { soluções recebidas de diferentes lugares. }\end{array}$ & $\begin{array}{l}\text { A abertura e o desejo de } \\
\text { compartilhar informações e } \\
\text { ideias entre os profissionais e os } \\
\text { usuários da informação ajudam } \\
\text { na compreensão e execução das } \\
\text { tarefas relacionadas à produção } \\
\text { da notícia. }\end{array}$ & $\begin{array}{l}\text { - Investimentos em aprendizagem de } 1^{\mathrm{a}}, 2^{\mathrm{a}} \mathrm{e} \\
3^{\mathrm{a}} \text { ordem contribuem para a ampliação das } \\
\text { percepções das equipes. } \\
\text {-O que impacta em autonomia, } \\
\text { autorresponsabilidade, fortalecimento de } \\
\text { identidade e outros aspectos que } \\
\text { favorecem à abertura para interagir com } \\
\text { ideias, informações, críticas e propostas de } \\
\text { soluções vindas de diferentes lugares e } \\
\text { observadores. }\end{array}$ & $\begin{array}{l}\text { - A exposição e a indagação de } \\
\text { diferentes pontos de vistas } \\
\text { contribuem de forma efetiva para a } \\
\text { produção da notícia. } \\
\text { - A coragem e abertura para a } \\
\text { exposição e indagação de ideias, } \\
\text { críticas e soluções, inclusive quando } \\
\text { se trata de opiniôes divergentes, são } \\
\text { necessárias para as redações } \\
\text { verdadeiramente comprometidas } \\
\text { com novas formas de configuração } \\
\text { das redes de colaboração e seus } \\
\text { novos meios e suportes de } \\
\text { comunicação digital. }\end{array}$ & $\begin{array}{l}\text { - Abertura para o novo em ambientes de } \\
\text { redações jornalísticas, está diretamente } \\
\text { relacionada à capacidade e } \\
\text { disponibilidade de escuta por parte dos } \\
\text { responsáveis pelo processo de } \\
\text { produção da notícia. } \\
\text { - A compreensão de que as diferenças de } \\
\text { opiniôes podem enriquecer o trabalho } \\
\text { faz parte do exercício de uma escuta } \\
\text { efetiva. }\end{array}$ \\
\hline $\begin{array}{l}\text { Necessidade de } \\
\text { constante } \\
\text { aperfeiçoamento } \\
\text { por parte dos } \\
\text { profissionais da } \\
\text { informação } \\
\text { (especialmente, em } \\
\text { tecnologias) e } \\
\text { motivação para } \\
\text { trabalhar e investir } \\
\text { em ambientes de } \\
\text { rápidas mudanças, } \\
\text { altamente } \\
\text { competitivos e que } \\
\text { dependem de } \\
\text { cooperação mútua } \\
\text { entre as pessoas. }\end{array}$ & $\begin{array}{l}\text { - A clareza com relação aos princípios e } \\
\text { diretrizes que orientam os } \\
\text { compromissos, o exercício de } \\
\text { preparação das atividades, o } \\
\text { monitoramento do que é executado e a } \\
\text { possibilidade de reflexões sobre os } \\
\text { trabalhos, contribui para explicitar o que } \\
\text { é necessário para a obtenção dos } \\
\text { resultados das redações e os tipos de } \\
\text { competências desejáveis para as } \\
\text { equipes. } \\
\text { - Também contribui para o melhor } \\
\text { aproveitamento das competências } \\
\text { disponiveis, alinhamentos entre os } \\
\text { objetivos profissionais das pessoas e da } \\
\text { organização, além do gerenciamento de } \\
\text { horários e agendas de trabalho. }\end{array}$ & $\begin{array}{l}\text { O respeito à identidade } \\
\text { (dignidade e integridade) dos } \\
\text { profissionais da informação } \\
\text { impactam diretamente no seu } \\
\text { desenvolvimento, no seu } \\
\text { relacionamento com os demais e } \\
\text { na capacidade de cumprir suas } \\
\text { tarefas assumidas. }\end{array}$ & $\begin{array}{l}\text { - A compreensão do impacto dos modelos } \\
\text { mentais com seus ciclos de aprendizagem } \\
-1^{\mathrm{a}}, 2^{\mathrm{a}} \mathrm{e} 3^{\mathrm{a}} \text { ordens }- \text { fornece insumos para } \\
\text { a realização de programas de } \\
\text { desenvolvimento das equipes. Tanto em } \\
\text { nível operacional (ação), quanto em nível } \\
\text { de reflexão (interpretação) ou em nível } \\
\text { mais profiundo (filtros e estruturas) que } \\
\text { norteiam as interpretações e ações dos } \\
\text { indivíduos. } \\
\text { - Essa compreensão apoia não apenas os } \\
\text { programas de capacitação das redações, } \\
\text { mas também as decisões de } \\
\text { aperfeiçoamento individual dos } \\
\text { componentes das equipes. }\end{array}$ & $\begin{array}{l}\text { - O expor e o indagar produtivo } \\
\text { contribuem para o } \\
\text { compartilhamento de desejos e } \\
\text { inquietações dos profissionais e das } \\
\text { organizações. } \\
\text { - Esse compartilhamento favorece o } \\
\text { entendimento sobre as necessidades } \\
\text { e possibilidades de aperfeiçoamento } \\
\text { de ambas as partes - tanto das } \\
\text { redações, quanto das suas equipes. }\end{array}$ & $\begin{array}{l}\text { Como é o escutar e não o falar que } \\
\text { confere sentido ao que é dito, escutas } \\
\text { efetivas são fundamentais para o } \\
\text { entendimento dos desejos e } \\
\text { inquietações que promovem o } \\
\text { aperfeiçoamento e motivação das } \\
\text { equipes. }\end{array}$ \\
\hline
\end{tabular}


Tendo como base a Figura 3, apresentada na seção 3.2, que sintetiza os marcos conceituais trabalhados neste artigo, a análise dos dados secundários, demonstrada na Matriz de Sentidos, evidenciou que o processo de produção de notícias no contexto de todas as redações visitadas acontece por meio de algum nível de coordenação de ações, constante e retroalimentado, onde cada etapa - princípios e direcionadores individuais e organizacionais, preparação, execução e avaliação/reflexão - mesmo que de forma não estruturada, envolve cuidados com: o cumprimento da tarefa (publicação das notícias), as relações entre os atores (repórteres, editores, fotógrafos, diagramadores, leitores, espectadores, jornais e agencias concorrentes, governo etc.) e a identidade (dignidade e integridade) das pessoas refletida na coerência entre os compromissos, intenções e ações dos profissionais da notícia e das redações visitadas. Modelos mentais, escuta efetiva, capacidade de exposição e indagação produtiva, além de aspectos relacionados a confiança e abertura para compartilhar inquietudes, foram observados como variáveis de apoio à realização das etapas relacionadas.

A análise dos dados secundários permitiu aos autores "escutar" o que não é dito de forma locucionária, mas sim de forma ilocucionária. Sendo possível acenar que as equipes das redações visitadas fazem o que fazem, com o melhor dos propósitos e com algum nível de efetividade, porque é o possível, em função do nível de competências conversacionais que possuem.

Isto posto, tal como apresentado na Matriz de Sentidos, o desenvolvimento de determinadas distinções permitiria às equipes perceberem ações executadas na fala (atos ilocucionarios) presentes por trás de palavras e sentenças expressas (atos locucionários). Essa análise abre espaço para reflexões sobre o que poderia ser feito para que as equipes possam melhorar o nível de efetividade (perlocucionário) das conversas voltadas para a articulação, execução e avaliação das ações responsáveis pela produção da notícia.

A Matriz de Sentidos contribui para a compreensão de que o desenvolvimento de novas distinções, relacionadas aos fundamentos teóricos investigados, permitiriam que aquilo que as equipes comumente identificam no dia a dia (percepções manifestas), passasse a ser identificado a partir de distinções que possibilitariam percepções mais profundas (além do que é manifesto) a respeito dos compromissos assumidos e do processo de coordenação de ações necessárias para cumpri-los.

Dessa forma, a relação entre as características dominantes das redações jornalísticas visitadas e as variáveis dos fundamentos teóricos investigados, apresentados na Matriz de 
Sentidos, fornece insumos ("achados") para o mapeamento dos tipos de competências conversacionais capazes de tornar os profissionais da informação (redatores, fotógrafos, editores, jornalistas) observadores distintos, aptos para desenvolver conversas efetivas e obter melhores resultados no processo de produção da notícia, tendo em vista as redes de colaboração e os novos meios e suportes de comunicação digital com os quais se relacionam.

\section{CONSIDERAÇÕES FINAIS}

O principal objetivo deste artigo foi analisar características das conversas em ambientes de redações jornalísticas, em particular, conversas para coordenação de ações e realização de compromissos relacionados ao processo de produção da notícia. Tal como apresentado, competência conversacional significa capacidade de, conversando, mobilizar, articular e colocar em ação, de forma sustentável, conhecimentos, habilidades, atitudes, valores e experiências necessárias para o desempenho eficiente e eficaz de atividades. Essa capacidade (de conversar) é o que move os esforços de coordenação de ações, mesmo não estruturadas, para produção da notícia. Logo, para que as redações alcancem resultados mais efetivos é preciso investir na forma como as equipes conversam. O que significa desenvolver suas competências conversacionais.

Uma das contribuições deste trabalho está em situar a importância das conversas para o processo de produção das notícias, dando-lhes visibilidade formal, teórica, filosófica e metodológica. Se as redações compreenderem que as conversas as fazem ser mais ou menos efetivas, será possível, não apenas dar maior visibilidade para os acontecimentos e as dinâmicas das equipes, mas também, e quiçá principalmente, protagonizar, de forma responsável, o aspecto ético da contribuição social ao se produzir e colocar no mundo as notícias produzidas pelas mídias informativas. Entretanto, conforme foi visto, a compreensão da importância das conversas exige observadores e ações diferenciadas, o que se adquire por meio de distinções próprias que associadas às percepções que temos como seres humanos nos fazem observadores diferentes. Então, o que significa transformar um observador em um observador diferenciado? Onde está a diferenciação? Acreditamos que observar é uma composição de "perceber" e "distinguir". Assim, um observador diferenciado desenvolve-se no nível das percepções e distinções que possui.

O estudo dos fundamentos teóricos e dos instrumentos de análise, em especial da Matriz de Sentidos, aqui apresentados, permitiram a observação das conversações presentes 
nas ações desenvolvidas pelas equipes das redações jornalísticas. A análise ontológica das principais características dominantes e comuns às redações visitadas, relacionadas às principais variáveis dos fundamentos teóricos investigados, forneceram aportes interessantes para a compreensão de importantes aspectos relacionados às competências conversacionais e ajudaram a elucidar achados (insumos) úteis para a promoção de mudanças nos comportamentos dos indivíduos e das equipes das redações visitadas. Uma vez observadas as dinâmicas conversacionais, é possível intervir sobre elas, trabalhando aspectos relacionados às percepções e distinções dos indivíduos, e assim, contribuir para a eficiência e eficácia das rotinas de produção da notícia realizadas por essas equipes.

Elaborada com base na TFD que busca compreender o fenômeno com base em dados emergentes, não em dados pré-concebidos, a Matriz de Sentidos mostrou que é possível fazer uma avaliação da relação entre o fenômeno observado e as dimensões ontológicas das conversas, no que diz respeito a seus níveis de ação. Esse instrumento contribuiu para a explicação de padrões de comportamentos, relacionados ao universo das competências conversacionais, presentes no processo de produção da notícia dos ambientes das redações visitadas. Com base na análise empreendida, este artigo propõe a ampliação deste estudo e apresenta a Matriz de Sentidos como um instrumento que pode ser customizado e replicado para outros contextos em que as conversações possuam um papel relevante.

A partir das informações aqui apresentadas, o estudo realizado permite afirmar que em ambientes de produção de notícia, conversas mais efetivas significam articulações de ações mais efetivas. Ações essas que envolvem o desenvolvimento de competências relacionadas à tríade T-R-I, ao ciclo de coordenação de ações, ao falar e ao escutar efetivo e a outros aspectos apresentados nas seções 2 e 3.2. O contato com uma fonte de informações, a realização de uma entrevista, uma reunião de pauta, a construção, a edição e a publicação de um conteúdo são alguns dos exemplos de dinâmicas que envolvem pessoas com perfis e especialidades distintas, atuando por meio das conversações. Conversas têm o potencial de construir realidades. A questão é: dadas as especificidades dos ambientes de redações jornalísticas e os contextos nos quais estão inseridas, que realidades as equipes de produção da notícia (equipes internas e externas à redação, formadas por colaboradores diretos e indiretos) estão preparadas para construir? Essa é uma reflexão apropriada para todos os envolvidos no processo de produção da notícia, em especial, os líderes e responsáveis pelo desenvolvimento de equipes. 
Por último, além das investigações, análises e contribuições aqui apresentadas, esta pesquisa revela a possibilidade de desdobramentos futuros dos estudos sobre as várias dimensões das conversas, em especial, na perspectiva da teoria da complexidade, que permitirá um olhar mais profundo sobre as dinâmicas existentes nas estruturas de compromissos (T-R-I), presentes nos ciclos de coordenação de ações e nas dimensões ontológicas das conversações que envolvem, além da linguagem, estudos sobre corporalidade e emocionalidade.

\section{REFERENCIAS}

ANDRADE, Eron. Conversas: o fator chave para o gerenciamento de projetos. Dissertação (Mestrado) - Universidade Católica de Brasília - UCB, Brasília, DF, Brasil, 2009.

AUSTIN, John Langshaw. How to do things with words. Boston: Harvard University Press. 1962.

ÁVILA, José Coelho; LUCENA FILHO, Gentil José; FIGUEIREDO, Rejane Maria. Competências Conversacionais para a Governança Corporativa. iSys - Revista Brasileira de Sistemas de Informação, 10, 85-110. 2017.

AVILÉS, José A. García; KALTENBRUNNER, Andy; MEIER, Klaus. Media convergence revisited: lessons learned on newsroom integration in Austria, Germany and Spain. Journalism Practice. Inglaterra: Londres, n. 8, 2014, p. 573-584.

BRAGA, Sônia de Oliveira. O. O coaching ontológico como instrumento de desenvolvimento de equipes de trabalho. Dissertação (Mestrado) - Universidade Católica de Brasília - UCB, Brasília, DF, Brasil, 2007.

BROWN, Brené. A Coragem de Ser Imperfeito. Rio de Janeiro: Editora Sextante. 2013.

LASORSA, Dominic; LEWIS, Seth.; HOLTON Avery. Normalizing twitter. Journalism Studies, 13:1, 19-36. 2012. DOI: 10.1080/1461670X.2011.571825.

ECHEVERRÍA, Rafael. Confiança viga mestra da empresa de futuro. Ethos Reflexão, 7, 1-26. 2002. URL: https://www.ethos.org.br/wp-content/uploads/2013/02/Reflex\%C3\%A3o071.pdf

ECHEVERRÍA, Rafael. El ciclo de la promesa: es labón básico de coordinación de acciones. Centro de aprendizaje y enseñanza. 1-26. 1998.

ECHEVERRÍA, Rafael. Ontologia del lenguaje. Santiago, Chile: Dolmen Ediciones, 1997.

FLORES, Fernando. Conversaciones para la acción. Inculcando una cultura de compromisso em nuestras relaciones de trabajo. Bogotá: Lemoine Editores. 2015.

FLORES, Fernando. Creando organizaciones para el futuro. Santiago, Chile: Dolmen Ediciones, 1996.

FLORES, Fernando. Promesas, confianza e identidad publica. Santiago de Chile: Redcom Chile S. A. 1-12. 1994. 
GASQUE, Kelley Cristine. Teoria Fundamentada: nova perspectiva à pesquisa exploratória. In Mueller, S. P. M. (Org.), Métodos para a pesquisa em Ciência da Informação (pp. 83-118). Brasília: Thesaurus. 2007.

HERAVI, Bahareh Rahmanzadeh; HARROWER, Natalie. Twitter journalism in Ireland: sourcing and trust in the age of social media. Information, Communication \& Society, 19, 1194-1213. 2016.

JENKINS, Henry. Cultura da convergência. $2^{\text {a }}$ edição. São Paulo: Aleph, 2009.

KOFMAN, Fredy. Metamanagement: a nova consciência dos negócios (Vols. 1-3). São Paulo: Antakarana Cultura, Arte e Ciência / Willis Harman House. 2002.

LENZI, Alexandre. Inversão de papel: prioridade ao digital, um novo ciclo de inovação para jornais impressos. Florianópolis: Insular, 2018.

LUCENA FILHO, Gentil José. Sobre conversações na Fundação Oswaldo Cruz - Fiocruz. Programa de desenvolvimento organizacional da Fiocruz. Brasília. 1-6. 2014.

LUCENA FILHO, Gentil José; CAMPOS, R.; Oliveira, S.; MORALES, M. (2012, October). A technontological framework to conversations for KM: conception and potential applications. Proceedings of 9th International conference on intellectual capital, knowledge management \& organizational learning - ICICKM, Bogotá, Colômbia.

LUCENA FILHO, Gentil José. Competências conversacionais: um diferencial no gerenciamento de projetos. MundoPM, 6, 75-80. 2010.

MATURANA, Humberto; VARELA, Francisco. A árvore do conhecimento: as bases biológicas do entendimento humano. São Paulo: Palas Athena. 2001.

OLIVEIRA, Edgard Costa. Relatório de Pós-Doutorado em Ciência da Computação. Universidade de Brasília - UnB, Brasília, DF, Brasil. 2017. Trabalho de conclusão de curso.

SANTOS, Ébida.; LENZI, Alexandre.; MEDEIROS Benedito; GHINEA George. Redações jornalísticas em contexto de convergência: um estudo comparativo exploratório no Brasil, na Costa Rica e na Inglaterra. Comunicação \& Inovação, v. 20, n. 43, 2019.

SEARLE, John Rogers. Actos de habla. Madrid: Cátedra. 1980.

SILVA, Jan Alyne Barbosa; PEREIRA, Maria de Lourdes; RIBEIRO, Rodolfo Silva. Estudo de caso das transformações no perfil do jornalista. Brazilian Journalism Research, v. 9, n. 2-2013, p. 50, 2013.

TÁRCIA, Lorena Peret Teixeira. Ação, pesquisa e reflexão sobre a docência na formação do jornalista em tempos de convergência das mídias digitais. Dissertação (Mestrado) - PUC, Minas Gerais, MG, Brasil, 2007.

TRAQUINA, Nelson. As notícias. [p. 167 a 176] In: TRAQUINA, Nelson. (org.). Jornalismo: questões, teorias e "estórias". Lisboa: Vega, 1993.

WINOGRAD, Terry; FLORES, Fernando. Understanding computers and cognition: A new foundation for design. Norwood, NJ: Ablex. 1998. 


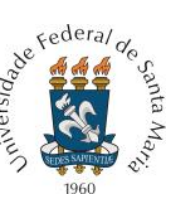

PROGRAMA DE PÓS-GRADUAÇÃO EM COMUNICAÇÃO DA UNIVERSIDADE FEDERAL DE SANTA MARIA

Original recebido em: 25 de março de 2019

Aceito para publicação em: 20 de março de 2020

\section{Ana Cristina Carneiro dos Santos}

Doutoranda em Ciência da Informação pela Universidade de Brasília com período sanduíche na Brunel University London. Mestre em Gestão do Conhecimento e Tecnologia da Informação pela Universidade Católica de Brasília, possui especialização em Educação pela Universidade Federal do Rio de Janeiro, extensão em Elaboração e Análise de Projetos pela Fundação Getulio Vargas, especialização em Planejamento e Análise de Sistemas pela União Educacional de Brasília e graduação em Tecnologia em Processamento de Dados pela Universidade Paulista. Atua como professora de graduação e pós-graduação. É especialista em Gestão da Complexidade com ênfase em Ontologia da Linguagem, além de certificada PMP (Project Management Professional) e consultora em gestão organizacional. Suas principais áreas de interesse e trabalho atual têm como foco as atividades de docência, pesquisa e consultorias relacionadas aos processos de articulação de ações e obtenção de resultados nas redes de compromissos organizacionais.

Gentil José de Lucena Filho

Professor universitário durante 38 anos, é Bacharel em Física (1972) e M.Sc. em Sistemas e Computação (1974) pela UFPB (1974) e Ph.D. em Systems Design (1978) pela University of Waterloo/Canadá (1978). Fez pós-doutorado em Inteligência Artificial, na Universidade Nova de Lisboa, Portugal, e tem cursos de especialização em Planejamento Estratégico e em Dinâmica de Grupos. Entre 1973 e 1998 foi Professor Adjunto na área de Ciência da Computação na Universidade Federal de Campina Grande (UFCG) e na Universidade de Brasília (UnB). Entre 1981 e 1998 também foi Analista Sênior de Ciência e Tecnologia do CNPq. De 1998 a 2011 foi Professor Adjunto e

Pesquisador na Universidade Católica de Brasília (UCB). É coach ontológico certificado e Pesquisador-chefe do Laboratório de Inteligência Conversacional - LabCon. Suas áreas de pesquisa hoje incluem: Aprendizagem Organizacional, Conversas nas Organizações, Coaching Ontológico, Gestão do Conhecimento e Desempenho de Equipes. No Labcon, desenvolve e dissemina a pesquisa e a aplicação prática do coaching e de competências conversacionais em instituições brasileiras.

\section{Gheorghita Ghinea}

Ph.D. (Computer Science) (1999, University of Reading, United Kingdom). Recipient (1999) of prestigious Overseas Research Scholarship in addition to 2 other scholarships. M.Sc. (Computer Science) with Distinction (1996: University of the Witwatersrand, S. Africa). B.Sc. (Hons) (Computer Science) with Distinction (1994 University of the Witwatersrand, S. Africa) - Recipient (1994) of the Chancellor s Medal awarded to The Most Distinguished Graduand in the Natural Sciences of the University of the Witwatersrand - Recipient of 5 other University awards and scholarships for my Honours study. B.Sc. (Computer Science, Mathematics) with Distinction (1993, University of the Witwatersrand, S. Africa). I am a Reader in Computer Science in the Department of Computer Science at Brunel University. Currently, my research pursuits are centered on extending the notion of multimedia with that of mulsemedia a term which I have put forward to denote multiple sensorial media, ie. media applications that go beyond engaging the by now traditional auditory and visual 


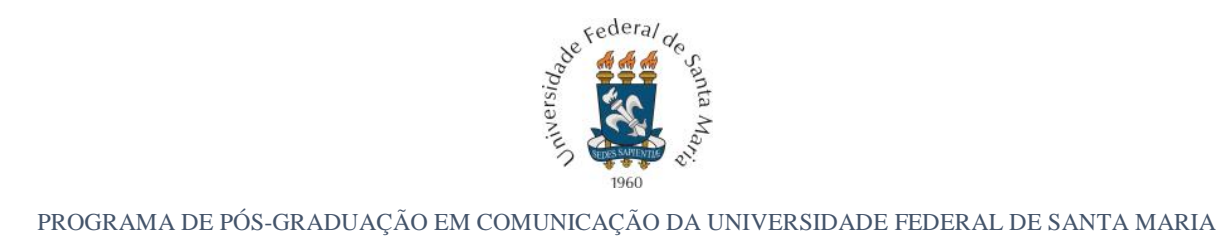

senses, engaging three of our other human in a realistic manner akin to our experiences of everyday

life. Research interests: Perceptual aspects of Digital Media, Multimodal Interaction and Eye Tracking, Pervasive and Ubiquitous Computing and Distributed and Interactive systems.

\title{
Lillian Maria Araújo de Rezende Alvares
}

Professora da Faculdade de Ciência da Informação da Universidade de Brasília (UnB), desde 2006, onde ocupou os cargos de Coordenadora do Curso de Graduação em Museologia entre 2010 e 2012 e Coordenadora do Programa de Pós-Graduação em Ciência da Informação (PPGCInf/UnB) de junho de 2012 a janeiro de 2014. Atualmente é Coordenadora do Curso de Graduação em Arquivologia. Pós-doutora pela Escola Superior de Tecnologia i Ciències Experimentals da Universitat Jaume I, Espanha. Doutora em Ciência da Informação pela Universidade de Brasília e pela Université du Sud Toulon-Var (Doctorat de Sciences de l'Information et de la Communication) em regime de cotutela em 2010. Especialista em Inteligência Competitiva pela Universidade Federal do Rio de Janeiro (UFRJ), Instituto Nacional de Tecnologia (INT) e Instituto Brasileiro de Informação em Ciência e Tecnologia (Ibict) em 2001. Mestre em Biblioteconomia pela Universidade de Brasília (1997) e Graduada em Engenharia Mecânica (1990) pela mesma universidade.

Ébida Rosa dos Santos

Doutora em Comunicação pela Universidade de Brasília (UnB). Mestra em Jornalismo pela

Universidade Federal de Santa Catarina (POSJOR UFSC). Graduada em Comunicação Social, com habilitação em Jornalismo, pela Universidade Federal de Santa Maria. Registro Profissional: Mtb 16154. Membro do grupo de pesquisa Ciência Tecnologia e Política (CTPOL) e do Núcleo de Estudos em Mídia e Política (NEMP).

\section{Maria de Fátima Ramos Brandão}

Doutora em Psicologia Social, do Trabalho e das Organizações pela Universidade de Brasília (2009), Mestre em Ciência da Computação pela Universidade Federal do Rio Grande do Sul (1984), Especialista em Coach Organizacional pela Newfield Consulting e UCB (2001) e graduada em Processamento de Dados pela UnB (1978). É docente fundadora do Departamento de Ciência da Computação da Universidade de Brasília. Coordena o Programa Rede de Extensão para Inclusão Digital - REID, iniciado em 2010 na UnB. Exerceu a função de Diretora Técnica de Graduação do Decanato de Ensino de Graduação e de Procuradora Institucional da UnB no período de 2013 a 2016.

Coordenadora Técnica do Projeto de Pesquisa MDM - Mídia Digital Multimodal no âmbito do Programa de Cooperação Internacional CAPES - PVE Subprograma 2014 e Coordenadora de Área no

Programa de Residência Pedagógica. Atua nas áreas de Educação e Formação Docente em Computação, Informática na Educação, Educação a Distância e Avaliação de Programas Sociais.

\author{
(-) $(190$ \\ Esta obra está licenciada com uma Licença \\ Creative Commons Atribuição-NãoComercial-CompartilhaIgual 4.0 Internacional
}

ANIMUS 